\title{
Variations in seed and seedling responses to water stress in three provenances of Eucalyptus camaldulen- sis Dehnh.
}

\author{
A. Gibson and E.P. Bachelard \\ Department of Forestry, Australian National University, Canberra, Australia
}

\section{Introduction}

Previous work (Bachelard, 1985, 1986a, b; Gibson and Bachelard, 1987; Yang et al., 1988) has shown that seeds and seedlings of eucalypt species, subspecies and provenances within a species may differ in their germination and growth responses to water stress. Seeds from 3 provenances of Eucalyptus camaldulensis Dehnh. differed in their abilities to germinate under different atmospheric vapour pressure deficits (VPD) and plate matric potentials in a manner consistent with the moisture conditions in the environment in which these provenances occur naturally (Gibson and Bachelard, 1987). In this study, the effects of water stress on the initial establishment and early growth of seedlings from 3 provenances of $E$. camaldulensis were examined.

\section{Materials and Methods}

The 3 provenances of E. camaldulensis (Katherine and Petford from monsoonal sites; Tennant Creek from a semi-arid site) were the same as those used previously (Gibson and Bachelard, 1987). The initial establishment (hypocotyl raised, cotyledons opened) of seedlings from germinated seeds placed on the surface of soils at different moisture contents $(35,18$ and $10 \%$, $w / w)$ in containers in a controlled environment cabinet was observed, and early seedling growth measured. Effects of water stress (10\% s.m.c. for $6 \mathrm{wk}$ ) on tissue-water relations, water use efficiency, partitioning of dry matter into roots, stems and leaves, leaf growth and morphology were also determined in 8 wk old seedlings grown in pots in a glasshouse with and without added fertiliser.

\section{Results}

Establishment and early seedling growth

Seedlings established from most seeds sown on the surface of soils at $35 \%$ s.m.c., with slightly fewer Katherine seedlings establishing (Table 1). Fewer seedlings established from seeds sown on $d 2$ due to the drying of the soil surface between $d 1$ and 2. At $18 \%$ s.m.c., Petford seedlings established best and Katherine seedlings worst. These differences in establishment were associated 
Table I. Seedling percent from E. camaldulensis seeds placed on soil surface on days 1 and 2 (means of 2 replicates).

\begin{tabular}{llrlllll}
\hline $\begin{array}{l}\text { Soil moisture } \\
\text { content }\end{array}$ & \multicolumn{2}{c}{ Katherine } & & \multicolumn{2}{c}{ Petford } & & \multicolumn{2}{c}{ Tennant Creek } \\
\cline { 2 - 3 } \cline { 5 - 7 } & 1 & 2 & & 2 & & 2 \\
\hline $35 \%$ & 67 & 54 & 92 & 81 & 87 & 70 \\
$18 \%$ & 29 & 0 & 98 & 85 & 63 & 0 \\
\hline
\end{tabular}

with differences between provenances in the production of hairs on the collar of germinating seedlings (Fig. 1), which bind the
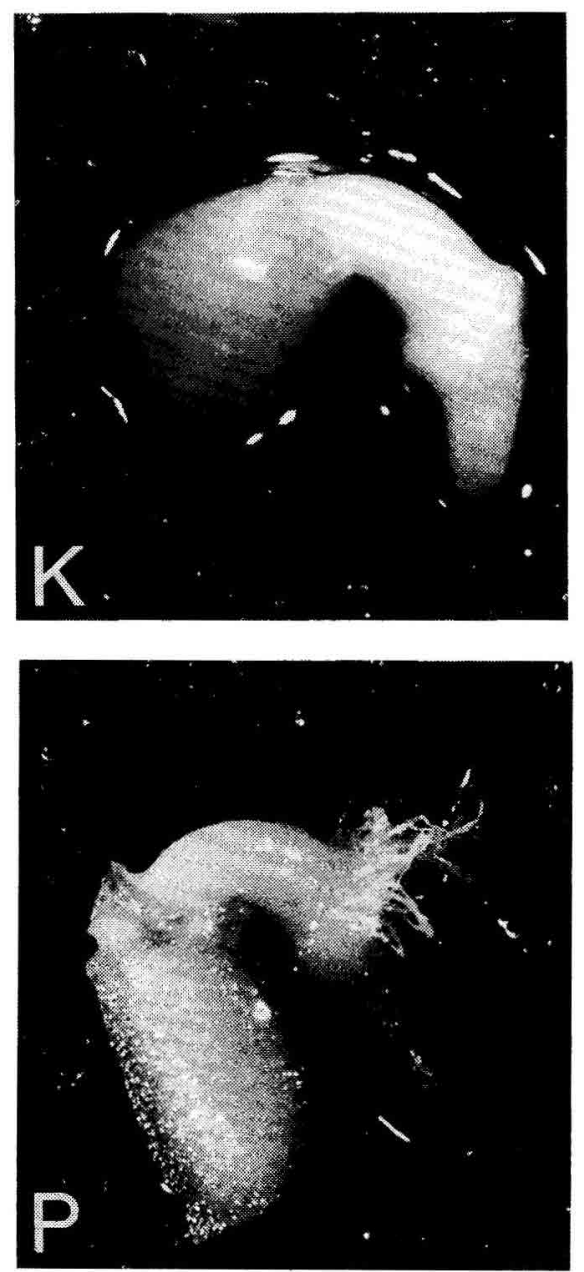

seedling firmly to the soil and assist early water uptake. Shoot growth of Petford seedlings was best at high s.m.c. but, at low s.m.c., the few Tennant Creek seedlings whose radicle penetrated the soil grew best (Fig. 2).

Response of older seedlings to water stress

Osmotic potentials of seedlings from all provenances were lowered similarly (by $0.1-0.3 \mathrm{MPa}$ ) by water and nutrient stress. Water use efficiency as measured directly

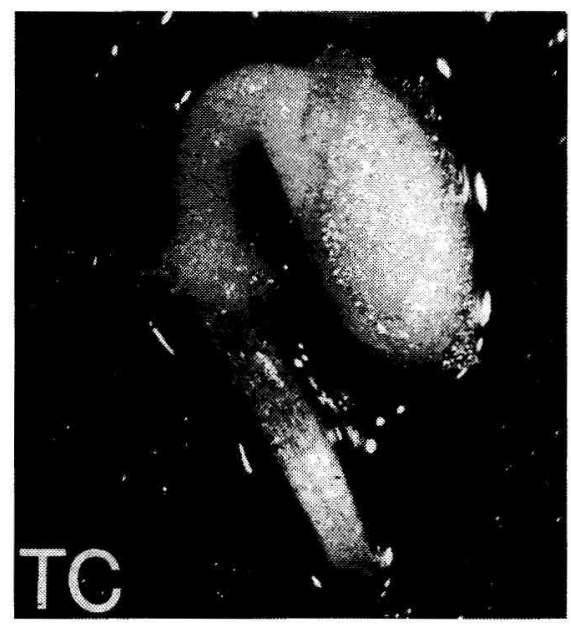

Fig. 1. Development of hairs on the collar of the hypocotyl of $E$. camaldulensis seedlings from Katherine (K), Petford (P) and Tennant Creek (TC) provenances. 

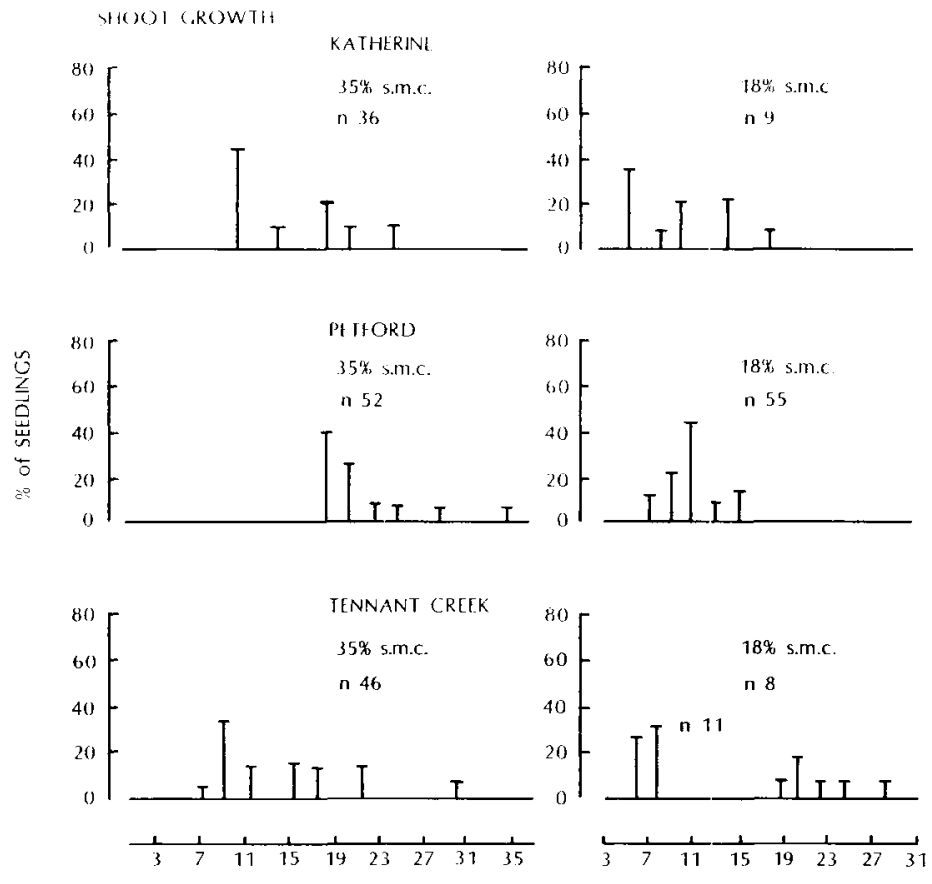

SHOOT IWt (mg) after 21 days

Fig. 2. Shoot growth of $E$. camaldulensic seedlings established from seeds gerrninated on the surface of soils at 35 and $18 \%$ s.m.c.

(g Dwt/kg water) and by carbon discrimination analysis (Farquhar and Richards, 1984) was significantly largest in waterstressed, fertilised Tennant Creek seedlings (Fig. 3).

Water stress reduced leaf area most in Katherine seedlings (Fig. 4), and the provenances also differed in stress-induced changes in the partitioning of dry matter into roots, stems and leaves (Fig. 5). Stressed Tennant Creek seedlings allocated more dry matter into leaves at the expense of roots, whereas the reverse situation prevailed in seedlings from the other 2 provenances. The proportion of dry matter distributed to stems was consistently lowest in Tennant Creek seedlings.
Both water and nutrient stress caused the leaves to become more linear (as opposed to lanceolate) in shape. Principal component analysis (Cooley and Lohnes,

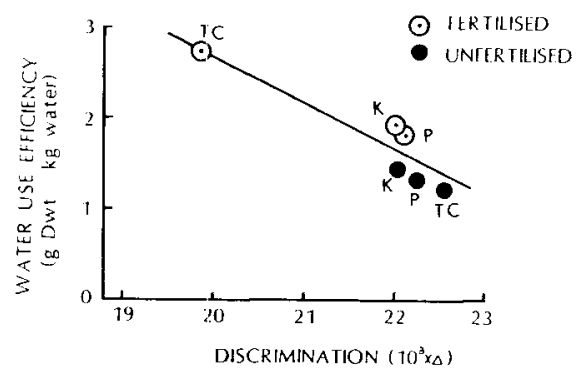

Fig. 3. Relationship between carbon discrimination and water use efficiency in $E$. camaldulensis seedlings from Katherine $(K)$, Petford $(P)$ and Tennant Creek (TC) provenances. 


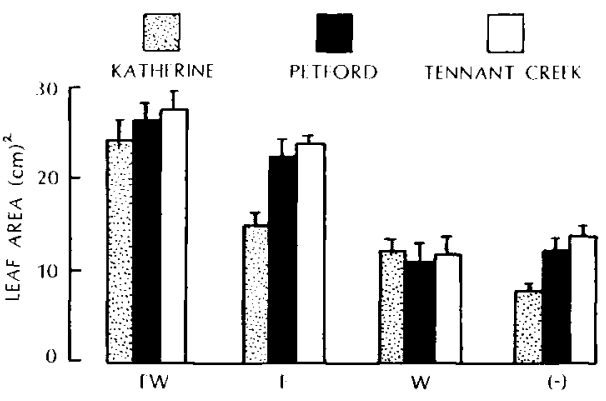

Fig. 4. Effect of fertiliser $(F)$ and water $(W)$ on the area of leaves formed during the treatment period by seedlings of $E$. camaldulensis.

1971) of the ratios of the width of a leaf to length at several positions along its length shows that Tennant Creek seedlings assumed the most linear leaf shape (most negative in Fig. 6). Leaf shape was affected most by nutrient stress in Tennant Creek and Petford seedlings, and by water stress in Katherine seedlings.

\section{Discussion and Conclusions}

The results indicate that the 3 provenances of $E$. camaldulensis differ in their adaptations to specific environments.
Seeds from the monsoonal Katherine provenance showed the least ability to germinate and its seedlings the least ability to establish, in dry environments. Petford seeds established best in dry environments and, although fewer Tennant Creek seedlings established, those which did establish and whose radicle penetrated the soil, grew best.

Leaf areas were reduced most by water stress in Katherine seedlings. Stressed Tennant Creek seedlings maintained a higher proportion of dry weight in leaves and least in stems and, in fertilised seedlings, those from Tennant Creek had the highest water use efficiency. The change to a linear leaf form which is associated with more arid conditions in provenances of $E$. camaldulensis (Andrew, 1973) was greatest in stressed Tennant Creek seedlings.

The responses of Petford seedlings were interesting, as although this is, like Katherine, from a monsoonal environment, its responses were intermediate between Tennant Creek and Katherine and, in several instances, it appeared the most adaptable provenance. It occurs naturally on well-drained, sandy, infertile soils and is developing a reputation as an outstandingly successful provenance in many plantations outside Australia. Speci-

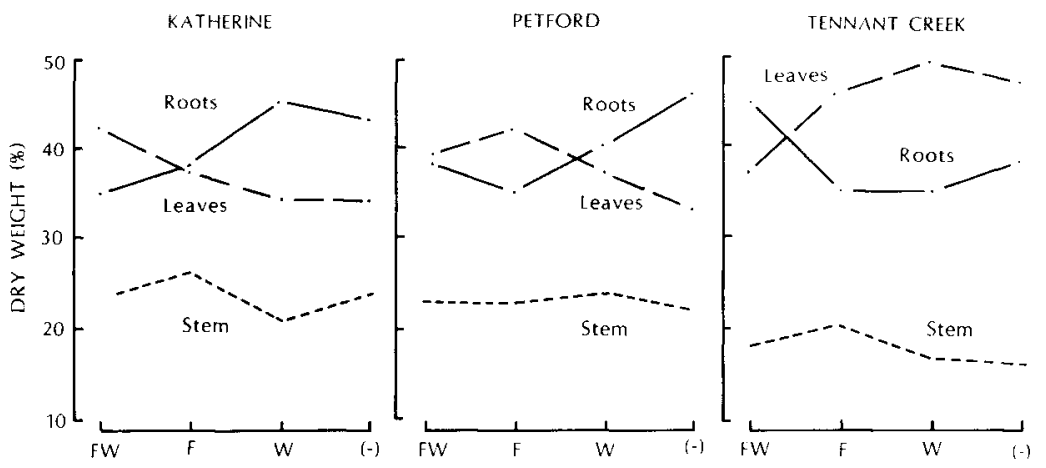

Fig. 5. Effect of fertiliser $(F)$ and water $(W)$ on the partitioning of dry weight into roots, stems and leaves of seedlings of $E$. camaldulensis. 


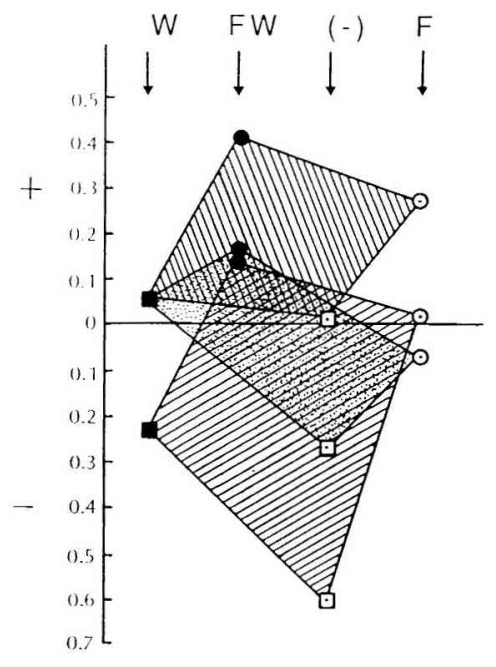

Fig. 6. Change in leaf shape due to fertiliser $(F)$ and water (W) in seedlings of $E$. camaldulensis from

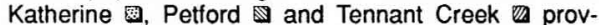
enances. + = increasingly lanceolate, $-=$ increasingly linear.

fic adaptations to their environment may have important consequences for the success of species and provenances within a species in plantations in alien environments.

\section{References}

Andrew I.A. (1973) Variation in leaf morphology among provenances of Eucalyptus camaldulensis Dehnh. grown in Rhodesia. Rhod. J. Agric. Res. 11, 155-169

Bachelard E.P. (1985) Effects of soil moisture stress on the growth of seedlings of three eucalypt species. 1. Seed germination. Aust. For. Res. 15, 103-114

Bachelard E.P. (1986a) Effects of soil moisture stress on the growth of seedlings of three eucalypt species. II. Growth effects. Aust. For. Res. 16, 51-61

Bachelard E.P. (1986b) Effects of soil moisture stress on the growth of seedlings of three eucalypt species. III. Tissue-water relations. Aust. For. Res. 16, 155-163

Cooley W.E. \& Lohnes P.R. (1971) in: Multivariate Data Analysis. John Wiley \& Sons, New York

Farquhar G.D. \& Richards R.A. (1984) Isotopic composition of plant carbon correlates with water-use efficiency of wheat genotypes. Aust. J. Plant Physiol. 11, 539-552

Gibson A. \& Bachelard E.P. (1987) Provenance variation in germination response to water stress of seeds of some eucalypt species. Aust. For. Res. 17, 49-58

Yang D., Bachelard E.P. \& Banks J.C.G. (1988) Growth and water relations of seedlings of two subspecies of Eucalyptus globulus. Tree Physiol. 4, 129-138 